\title{
Remanence of sentence prosody in Romance languages
}

Philippe Martin

LLF, UFR Linguistique, Université Paris Diderot Sorbonne Paris Cité

https://doi.org/10.36505/ExLing-2016/07/0001/000260

\begin{abstract}
Romance languages use surprisingly similar melodic contours to encode the sentence prosodic structure. The fact that these contours are governed by similar prosodic grammars and that similar stress rules are also applicable to these languages (except on French deprived of lexical stress) suggests that these phonological facts are inherited from Latin without much change, despite the constant evolution occurred during twenty centuries.

Key words: intonation, prosody, Romance languages, stress, prosodic grammar
\end{abstract}

\section{Introduction}

Sentence intonation is always present in the linguistic communication, even in silent reading. We cannot process language, whether in oral or written form, without decoding the prosodic structure intended by the speaker or recover (or approximate) the intonation intended by the writer. Indeed, due to memory limitations, it is not possible to retain long lists of objects such as words or syntagms without structuring these lists by some hierarchical grouping. Remembering large numbers or long lists of digits as found in telephone or credit card numbers requires to structure this information into small chunks, eventually organized into two or more levels, in order to form a structure. In these specific cases, where digits lack of any morphological information, only the prosody, organized into a prosodic structure, that will give to the listener enough indications to restore the intended structure of the data. In reading, this role is devoted to graphic indicators such as blanks separating groups of digits or of words. In speech communication, although many morphological or grammatical tools are available to recover a structure from the sequence of syllables pronounced by a speaker, it is again the prosodic structure which provides the first and essential hints to decode the sentence structure.

\section{The Romance language family}

The concept of language family is well known, and can be traced back to the XIX $^{\text {th }}$ century or earlier. The membership of a given language to a specific family is established by comparisons of lexical, syntactic,

ExLing 2016: Proceedings of $7^{\text {th }}$ Tutorial and Research Workshop on Experimental Linguistics, 27 June - 2 July 2016, Saint Petersburg, Russia 
phonological and phonetic similarities between languages candidates, leading to the virtual reconstitution of non-attested languages that would be the mother of the family. Examples of such well documented families are Nordic (including English, German, Dutch, Norks, Swedish, Danish...), Romance (French, Italian, Spanish, Portuguese, Catalan, Romanian...) or Turkic (Turkish, Mongolian, Sakha...).

Whereas comparative linguistics deals with phonetic, phonological, lexical and syntactic data, few scholars did compare prosodic features such as stress location, not to mention properties and grammar of melodic contours indicating the sentence prosodic structure. One notable exception is Paul Garde $(1968,2013)$ who gives simple and convincing word stress placement rules in various language families, including Romance. Comparison of prosodic features in Romance has been also the subject of two recent books. One, edited by Frota and Prieto (2015) operates in the Autosegmental-Metrical framework to compare phonetic and phonological features of many Romance languages, actually mixing both types of phonetic and phonological properties. The other (Martin, 2015) conducts its comparisons in the incremental prosodic structure framework, aiming to better establish the similarities between a phonological description of prosodic properties, carefully separated from phonetic differences. The adopted framework allows to establish clear similarities between prosodic systems in the languages considered (Italian, Spanish, Catalan, Italian, Romanian) as well as the important differences present in the system of French.

\section{Intonation in Romance}

Investigate similarities of prosodic structures in Romance languages involves three main topics:

Stressed syllable location

Melodic contours on stressed syllables

Grammar of melodic contours in the prosodic structure

In the Romance languages considered, Italian, Spanish, Catalan, European Portuguese and Romanian, prosodic markers, instantiated by melodic contours, appear surprisingly similar in these three categories: similar stressed syllable placement rules are applicable, similar phonological melodic contours are revealed through acoustic analysis, and the distribution of melodic contours in the sentence are described by the same grammar (Martin, 2015). Being so comparable, would these features be also valid for classical Latin from which the Romance 
languages are derived, leading to the reconstitution of Latin sentence prosody?

\section{Stress syllables in Latin}

It is remarkable that the position of lexical stress in most Romance languages can be traced back to Latin despite twenty centuries of phonetic, phonological and syntactic evolution. Classical Latin had five phonological vowels, $|\mathrm{i}||\mathrm{e}||\mathrm{a}||\mathrm{o}|$ and $|\mathrm{u}|$ (the vowels included in today Latin computer Latin fonts). Each vowel can be short or long so that the vocalic system includes five short and five long vowels. Latin has also three diphthongs, $|\mathrm{aj}|,|\mathrm{oj}|$ and $|\mathrm{aw}|$, written ae, oe, au.

The stress rule is as follows (Alkire and Rosen, 2010): stress is located on the penultimate syllable if this syllable is heavy, i.e. a diphthong, a long vowel or a vowel ended by a consonant. If the penultimate is light, stress falls on the prepenultimate syllable. If the penultimate syllable is neither closed by a consonant and neither a diphthong, stress is predictable only if we know that its syllable vowel is long or light (which is a property of the lexicon). If the word has only two syllables, stress falls on the penultimate, and if it has only one syllable, this unique syllable is stressed (but only if the word is a noun, an adjective, an adverb or a verb).

The following examples illustrate theses different cases:

in.fer.no has its second syllable closed by the consonant $|\mathrm{r}|$ and is therefore heavy, so that the penultimate is stressed: inferno.

The syllable mi in a.mi.ca "friend" contains a long vowel, and the stress is therefore on the penultimate: amica.

The syllable ro in au.ro.ra "dawn" has a light vowel, then the stress of aurora falls on the prepenultimate: aurora.

The word sp.ina "plug" has only two syllables. Since there is no other possibility, its first syllable, whether light or heavy, is stressed: $\boldsymbol{s p i n a .}$

\section{Stressed syllables in Romance languages}

The position of stress in Romance languages is restricted to a six-syllable window at the right edge of the word (six syllables for verbs and generally up to four syllables for nouns, adjectives, adverbs and other grammatical categories) and is determined by the same morphological rule, originally suggested by Paul Garde $(1968,2013)$. This rule is based on 1) the stress rules in Latin; 2) a morphological analysis of nouns, adjectives and verbs into their morphological structure and 3) the stressability of suffixes and flections: 
$($ prefix $)+$ stem $+($ suffixes $)+($ flections $)$

Suffixes and flections can be classified as stressable and unstressable, i.e. susceptible to be stressed, or not susceptible to be stressed (unstressable). As most lexical entries in Italian are derived from Latin (excluding borrowed words), the stem follows the Latin stress rule given above.

The stress rule for Romance languages (except French) is very simple: the last stressable morphological element (stem, suffix, flexion) of the word determine the position of the stressed syllable. Given the relatively large number of suffixes and flections homographs, it is important to match corresponding morphological categories (i.e. suffixes and flections for verbs, nouns and adjectives), in order to obtain a correct morphological analysis.

Things may appear occasionally more complicated with homographs either belonging to distinct grammatical categories, or worse (for a computer program) to the same category. An often quoted example in Italian is sono cose che capitano capitano "these are things that happen captain", where the first capitano is a verb $\left(3^{\text {rd }}\right.$ person singular of the verb capitare) and is stressed on the fourth syllable from the end, whereas the second capitano is a noun (here in its singular masculine form) and is stressed on its penultimate syllable.

Examples of homographs can belong to the same grammatical category. Examples in Italian are principi "princes" and principi "principles", or turbine "whirlwind" (singular, il turbine) and turbine "turbines" (plural of la turbina).

An example of homograph in Spanish: célebre "famous", celebre (from celebrar, "to celebrate" 3rd person present subjunctive of celebrar, "to celebrate"), celebré "I celebrated".

Some examples of various stress placement resulting from the general rule are given below.

\section{Stress on the last syllable (oxyton)}

Italian: tronco: virtü "virtue", caffé "coffee", amerò "I will love" (marked in the orthography by a stress mark);

Spanish: agudas: conversar "converse", pastor "pastor", oración "prayer " (sometimes marked in the orthography by a stress mark);

Catalan: agudas: nació "nation", després "after", valor "valor"

Portuguese: agudas: ruirãa 0 "they will collapse"

Romanian: tronco: cercetator "researcher", cobor "I descend" 
Stress on the penultimate syllable (paroxyton)

Italian: piano: amare "To love", nationale "national"

Spanish: llanas: iibro "book", difíicil "difficult", ángel "angel", (sometimes marked in the orthography by a stress mark);

Catalan: llanas, plana: Barcelona "Barcelone", plaşa "place", lingüissta "linguist"

Portuguese: plana: duiida"he doubts", falaram "they spoke", túnel"tunnel"

Romanian: paroxytone: fântâna 'fountain'

Stress on the antepenultimate syllable (proparoxyton)

Italian: sdrucciolo: telefono "telephone", celebre "famous", prendilo "Take it"

Spanish: esdrújulas: préstamo "let's loan", hipócrita "hypocritical", agnóstico "agnostic", crédito "credit|", (always marked in the orthography by a stress mark);

Catalan: proparoxítono, esdrújulas: típica "typical", política "politic", (always marked in the orthography by a stress mark);

Portuguese: proparoxytone: dúvida "doubt" (noun), dinâmicos "dynamic", lâmpada "lamp"

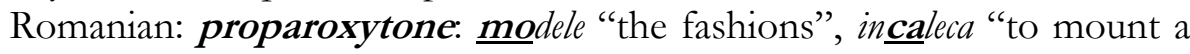
horse"”

Stress on the anteantepenultimate syllable (preproparoxyton)

Italian: bisdrucciole: caustico "caustic", fabbricalo "fabricate it"

Spanish: sobreesdrújulas: cómetelo "eat it", tráemela "bring it to me", (always marked in the orthography by a stress mark);

Catalan: sobreesdrújulas: transpórtaselo "transport it", trágatelo "swallow it" (always marked in the orthography by a stress mark);

Romanian doisprezece "twelve", lingurile "the spoons", veveriță "squirrel"

Stress on the anteanteantepenultimate syllable (Prepreproparoxyton)

Italian: trisdrucciole: fabbricalmelo "fabricate it for me"

Spanish: (http://www.romaniaminor.net/ianua/Ianua11/01.pdf)

Romanian: siaptesprezece "seventeen"

Stress on the anteanteanteantepenultimate syllable (preprepreproparoxyton)

Italian: quadrisdruciole: fabbricalmecelo "fabricate it for me to him"

Romanian: siaptesprezecelea "seventeenth" 


\section{Stressed syllables in French}

French has no lexical stress, only a group stress. Progressively from Old French, all segmental units following the accented syllables were dropped, at the exception of a single mute [ə] in certain cases. By this process, the position of stress lost its function of marking morphological boundaries as in the other Romance languages. From lexical the stress became demarcative in French, indicating boundaries not of words but of groups of words, whether content and grammatical, or even of single syllables.

\section{The Incremental Prosodic Structure}

The second step in comparing Romance languages prosodic features pertain to melodic contours located on stressed syllables, as these contours are assumed to instantiate prosodic markers indicating the prosodic structure. From the analysis of various examples with increasing syntactic complexity, it is possible to infer a grammar of intonation that would show striking similarities between Romance languages (again except French), despite possible experimental uncertainties pertaining to the assumed congruence between prosody and syntax in the data (Martin, 2015).

The prosodic structure is defined as a hierarchical grouping of minimal prosodic units, instantiated by accent phrases (aka prosodic words, stress groups...). These groupings, operated dynamically along the time axis by the listener to reconstitute the prosodic structure intended by the speaker, is indicated by prosodic markers instantiated by melodic contours located on accent phrases stressed syllable which has no emphatic function. In certain configurations, melodic contours located on accent phrases final syllables, if not stressed, are part of a complex prosodic marker together with the melodic change located on the stressed syllable. If the accent phrases last syllable is stressed, the complex contour results from a two distinct melodic movements occurring partly on the stressed syllable and partly on the final syllable of the accent phrase.

The melodic movements located on accent phrases stressed (and final) syllables are not realized at random. Their acoustical characteristics in term of rise or fall, high or low, long or short, constitute the material to implement phonological features which indicate dependency relations between accent phrases. These dependencies operate "to the right", i.e. towards another accent phrases carrying a specific contour planned in the immediate future by the speaker, to indicate that the given accent phrases (or all accent phrases already part of a group ended by the given 
accent phrases) carrying the first contour has to be merged with another accent phrases carrying the other contour placed further in the sentence from which it depends. For example, in French, the occurrence of a welldocumented contour usually called continuation majeure (after Delattre, 1966), presupposes the occurrence of a terminal conclusive contour later in the sentence. In terms of dependency relations, the continuation majeure depends on the assumed occurrence of a final conclusive contour ending the sentence, even if it will appear in the future of the pronounced sentence.

The dependency relations indicate to the listener how and when to merge the prosodic syntagms (a group of accent phrases) ended by a continuation majeure and by a terminal conclusive contour to form the overall prosodic structure of the sentence. The dependency relations are not limited to the grouping of continuation majeure and terminal contour. They function as well at lower levels of the prosodic structure, where other types of contour do indicate a relation of dependency towards a continuation majeure, etc.

\section{Prosodic grammar}

The object of prosodic research is to determine the phonological features of the contours located on accent phrases stressed syllables, and to discover the underlying grammar which implement the dependency relations between contours. Another remarkable point pertains to the time linear properties related to the processes of encoding and decoding the prosodic structure. Considering that prosodic events instantiated by melodic contours occur not simultaneously but one after the other on the time line instantiated by the sequence of syllables, it can be shown (Martin, 2015) that it is necessary and sufficient to evaluate dependency relation between two consecutive contours, provided a ranking between phonological contours has been established.

If $\mathrm{C} 0, \mathrm{Cc}, \mathrm{C} 1, \mathrm{C} 2, \mathrm{Cn}$ designate classes of prosodic events instantiated by melodic contours located on accent phrases stressed syllable (and essentially on its vocalic nucleus) defined as follows:

C0: terminal conclusive contour (declarative case), falling and low

Cc: complex contour, flat or slightly falling on the accent phrase stressed syllable, and rising on the accent phrase final syllable

C1: rising above the glissando threshold (i.e. above a parametric rate of melodic change)

C2: falling above the glissando threshold

Cn: neutralized, falling, flat or rising below the glissando threshold 
The ranking of prosodic contours in French is $\mathrm{Cn}<\mathrm{C} 2<\mathrm{C} 1<\mathrm{C} 0$, and presents an inverted ordering $\mathrm{C} 1<\mathrm{C} 2$ for the other Romance languages: $\mathrm{Cn}<\mathrm{C} 1<\mathrm{C} 2<\mathrm{Cc}<\mathrm{C} 0$.

Given these differences, the prosodic grammar operates the same way in French and in the other Romance languages. By comparing two successive melodic contours, say $\mathrm{Cx}$ and $\mathrm{Cy}$, relative to their ranking, the listener is able to assemble or not the prosodic words implied:

if $\mathrm{Cx}<\mathrm{Cy}$, the accent phrases attached to $\mathrm{Cx}$ and $\mathrm{Cy}$ are merged [Cx $\mathrm{Cy}]$

else if $\mathrm{Cx}=\mathrm{Cy}$, the accent phrases attached to $\mathrm{Cx}$ and $\mathrm{Cy}$ are part of a list, to be terminated by the occurrence of a contour of higher rank $[\mathrm{Cx}$ Cy ...

else if $\mathrm{Cx}>\mathrm{Cy}$, the accent phrases attached to $\mathrm{Cy}$ is not merged with the one attached to $\mathrm{Cx}[\mathrm{Cx}[\mathrm{Cy} \ldots$

This process is local as it involves only differences between two successive contours in the same domain. The examples of Fig. 1 (Italian), Fig. 2 (Portuguese) and Fig. 3 (French) illustrate the mechanism of local dependency relations leading to the (re)construction of the prosodic structure, using the same set of melodic contours and the same prosodic grammar. The resulting prosodic structures presented in these figures show different cases of local non-congruence with syntax.

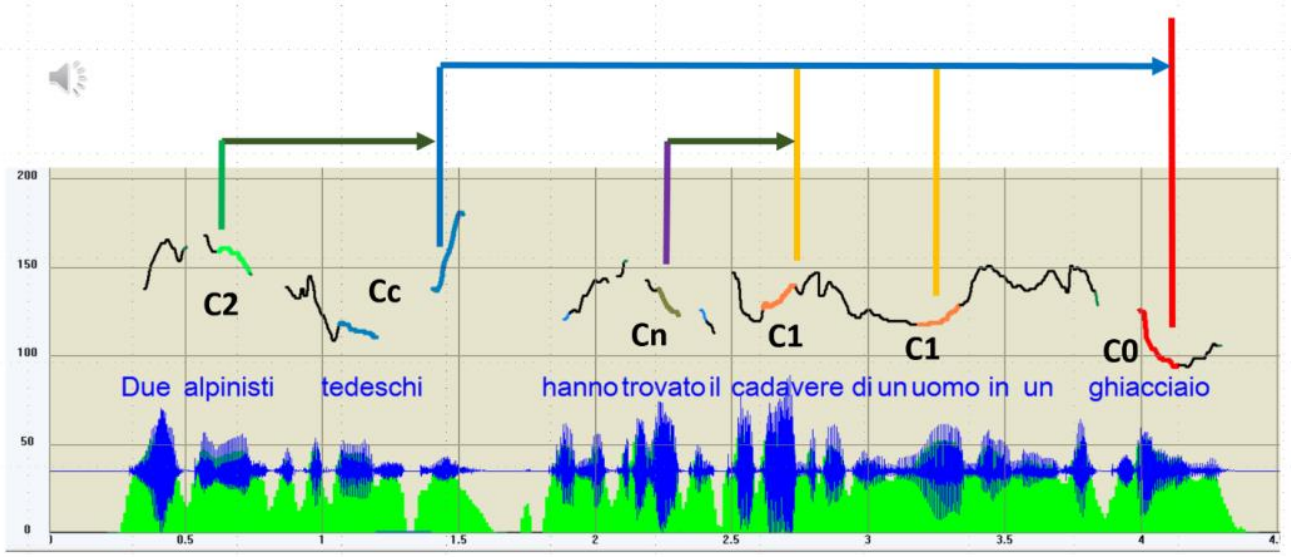

[Due alpinisti tedeschi] [[hanno trovato il cadavere]] [di un uomo] [in un ghiacciaio]]

Figure 1. Italian example of prosodic structure built by increments along time axis. 


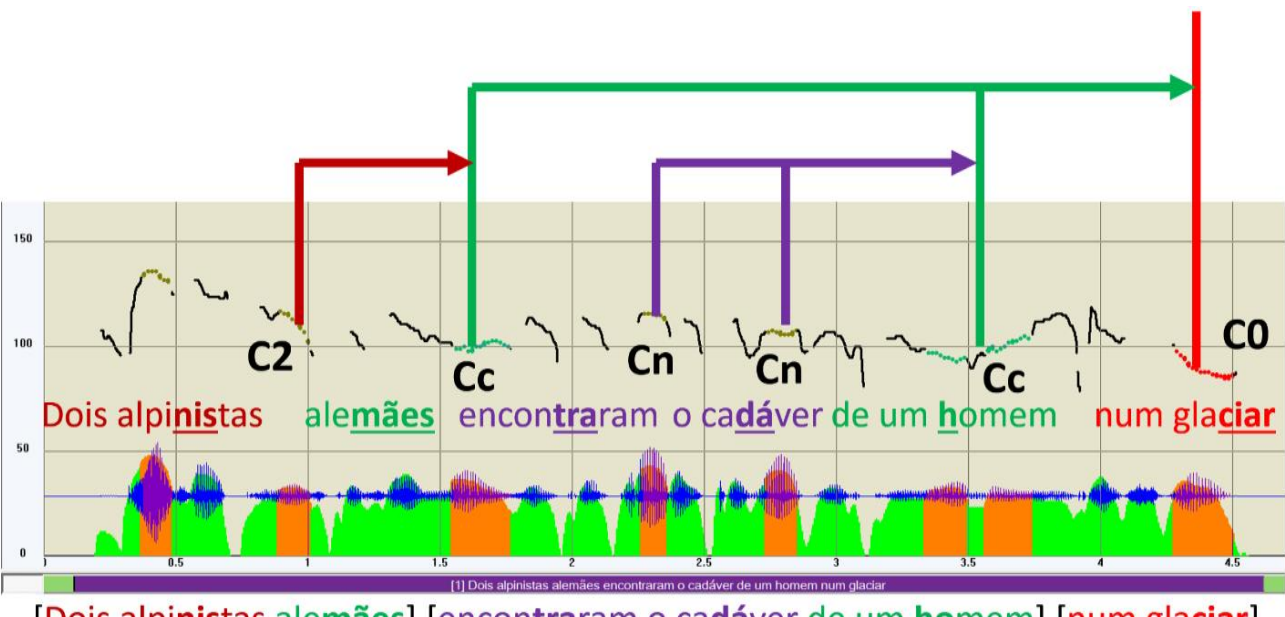

[Dois alpinistas alemães] [encontraram o cadáver de um homem] [num glaciar]

Figure 2. Portuguese example of prosodic structure built by increments along time axis.

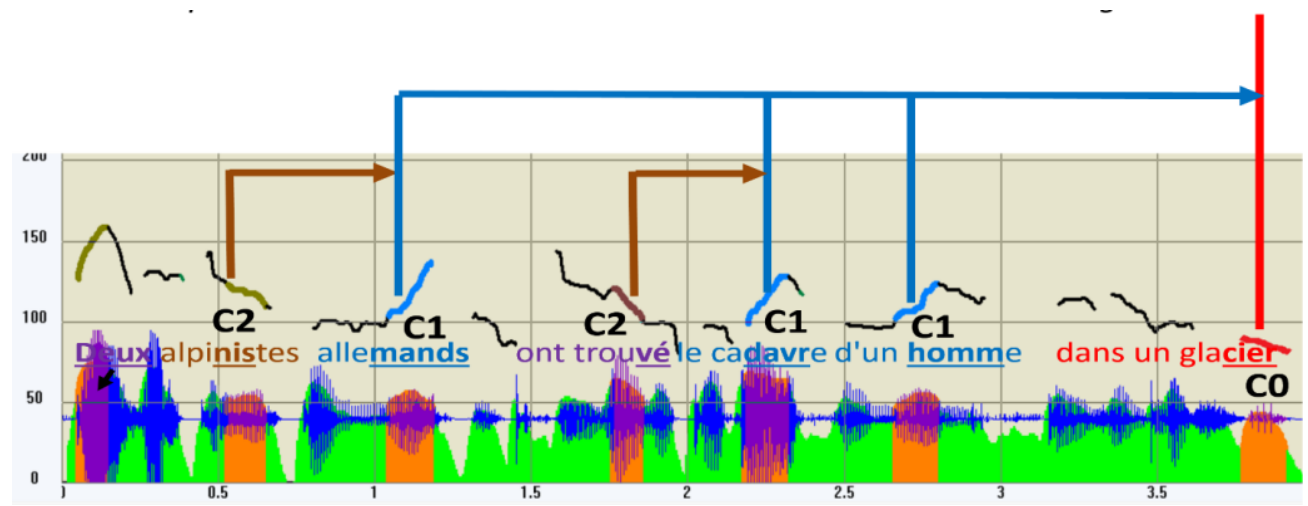

Figure 3. French example of prosodic structure built by increments along time axis.

\section{Conclusion}

No language is likely to escape the constrain of generating and decoding the sentence prosodic structure. However, it may be more surprising that Romance languages (except French) would use the same phonological melodic contours and the same grammar of intonation to encode the prosodic structure, leading to suggest that the melodic contours and the grammar that describe their use are inherited from Latin, despite the large differences in phonology, morphology and syntax existing among the languages derived from Latin.

The remanence of phonological prosodic features among Romance languages (including French when the absence of lexical stress is considered) is remarkable and pertain to the following topics: 
The position of lexical stress

The classes of melodic contours

The grammar of melodic contours as dependency markers between accent phrases

Stress placement in the accent phrase is clearly derived from the classical Latin stress rules, with the addition of suffixes ad flexions classified as stressable or unstressable. The same simple stress rule applies to all Romance languages. Classes of melodic contours are phonologically similar, with the exception of French which has no complex contour $\mathrm{Cc}$ since it has no lexical stress. Finally, the principle of contrast of melodic slope also applies to all Romance languages, French deprived of the complex contour $\mathrm{Cc}$ using another ranking in the prosodic grammar $\mathrm{Cn}>\mathrm{C} 2>\mathrm{C} 1>\mathrm{C} 0$, instead of $\mathrm{Cn}<\mathrm{C} 1<\mathrm{C} 2<\mathrm{Cc}$ $<\mathrm{CO}$.

\section{References}

Alkire T., C. Rosen, 2010. Romance Languages, an Historical Introduction, Cambridge University Press.

Delattre P. 1966. Les dix intonations de base du français, French Review 40, 1-14.

Garde P. 1968. L'accent, PUF, Paris, 172 p. / (2013) Lambert-Lucas, Paris.

Martin, Ph. 2015. The Structure of Spoken Language. Intonation in Romance, Cambridge University Press.

Frota, S., P. Prieto (eds.), 2015 Intonation in Romance. Oxford University Press. 